\title{
On the estimation of hydraulic conductivity of layered vadose zones with limited data availability
}

\author{
Smaranika Mahapatra* ${ }^{(0)}$ and Madan K Jha \\ AgFE Department, Indian Institute of Technology, Kharagpur 721 302, India. \\ ${ }^{*}$ Corresponding author.e-mail: smahapatra44@gmail.com
}

MS received 31 August 2017; revised 22 March 2018; accepted 24 July 2018; published online 15 March 2019

Vadose zone acts as a controlling agent for recharge and transport of contaminants into aquifers. Hence, for modelling and quantifying flow and transport processes in subsurface environments, hydraulic conductivity $(K)$ of the vadose zone plays an important role. However, given the heterogeneity and anisotropy of subsurface systems, the in-situ measurement of $K$ is a daunting task at a larger scale. The present study was conceived to evaluate the efficacy of salient pedotransfer functions (PTFs) to indirectly estimate the saturated hydraulic conductivity $\left(K_{\mathrm{s}}\right)$ of a lateritic vadose zone of eastern India. Also, in-situ hydraulic conductivity along with basic soil physical properties was determined in different vadose-zone layers at three locations (bare plot, cultivated field and orchard). Four PTFs [Campbell, Rawls-Brakensiek/Cronican-Gribb (R-B/C-G), and Models 2 and 3 of Rosetta] were selected to estimate $K_{\mathrm{s}}$ and their performances were evaluated. Based on the statistical indicators, it is concluded that Model 3 of Rosetta is capable of predicting relatively close values of $K_{\mathrm{s}}$ for the lateritic vadose zones to some extent. To generalise the findings of this study, it is recommended that such field-based studies should be carried out at a larger scale in lateritic terrains with varying land use/land cover.

Keywords. Lateritic vadose zone; saturated hydraulic conductivity; field-saturated hydraulic conductivity; pedotransfer functions; vadose-zone characterisation.

\section{Introduction}

Vadose zone is the intrinsic part of the water cycle that essentially controls the interrelationship between different water balance components such as precipitation, infiltration, evapotranspiration and groundwater recharge. It controls water and contaminant transport from the surface to groundwater and vice versa, acting as a buffer zone between land surface and underlying aquifer (Nimmo 2005). The physical and hydraulic characteristics of the vadose zone are generally poorly known due to its relative inaccessibility (in comparison to soil) and the comparative lack of historical research in this area at a larger scale (Dann et al. 2009).

Increasing concerns regarding the environmental impacts of different land use and development activities on groundwater resources have led to a considerable focus on the development of flow and transport models to understand, analyse and predict flow and contaminant transport processes in the vadose zone. These models require knowledge on soil hydraulic properties such as hydraulic conductivity, among other inputs, for evaluating the impact of past, present or proposed agricultural practices and environmental factors on groundwater systems. Given the importance of 
hydraulic conductivity, some direct methods have been developed for the determination of hydraulic conductivity in laboratory and field (Bouwer 1966; Libardi et al. 1980; Daniel 1982; Elrick et al. 1989; Reynolds and Elrick 1989; Bagarello et al. 2012). In spite of several comparative studies related to the determination of soil hydraulic conductivity for varying soils in the past (e.g., Lee et al. 1985; Gupta et al. 1993; Zhang et al. 2007; Jačka et al. 2014; Balfour 2015; Hangen and Vieten 2018), it is still a very difficult task to acquire appropriate data for specific applications as the field and laboratory methods are expensive, cumbersome and time consuming. To overcome this problem, indirect methods such as pedotransfer functions (PTFs) are used. Concerns in the last few decades regarding the contamination of groundwater due to agricultural and other man-made activities have led to a greater interest and more focused site-specific research on the estimation of hydraulic parameters in the field of vadose-zone hydrology.

In recent years, PTFs have been developed and used by many researchers across the world to estimate the hydraulic conductivity using easily available or measurable soil properties and also they have evaluated the performance of PTFs for various soils and regions (e.g., Wösten et al. 1995; Tietje and Hennings 1996; Pachepsky et al. 1999; Minasny and McBratney 2000; Sobieraj et al. 2001; Wagner et al. 2001, 2004; Cronican and Gribb 2004; Ungaro et al. 2005; Li et al. 2007; Manyame et al. 2007; Balland et al. 2008; Rasoulzadeh and Yaghoubi 2011; Duan et al. 2012; Puhlmann and von Wilpert 2012; Wang et al. 2012; Yao et al. 2015; Zhao et al. 2016). However, to date, no single PTF is available which can be used universally for varying soil types (Zhang et al. 2007). For example, Minasny and McBratney (2000) evaluated the predictability of eight PTFs against various field and laboratory measured saturated hydraulic conductivity values for a wide range of Australian soils. They found that the PTFs by Cosby et al. (1984), Dane and Puckett (1994) and Schaap et al. (1998) perform best for sandy, loamy and clayey soils, respectively. For all soil-textural classes of Germany, Wagner et al. (2001) reported that the PTF developed by Wösten (1997) performed the best among eight other well-known PTFs for predicting unsaturated hydraulic conductivities. In another study, Wagner et al. (2004) found the same PTF suitable for the deeper ground sediments (up to $100 \mathrm{~m}$ depth) of the Molasse basin in Germany. Manyame et al. (2007) found the van Genuchten model to be the most accurate method among three PTFs including Campbell and Vauclin for predicting the unsaturated hydraulic conductivity of the sandy soils at two villages in Niger. On the other hand, Li et al. (2007) developed a location-specific PTF for the Fengqiu County soils (sand, loamy sand, sandy loam, silty loam, silty clay loam and silty clay) sampled at seven different soil profiles of North China Plain. They compared the estimated saturated hydraulic conductivity values with those obtained by four existing PTFs, and found that the developed PTF performed the best for the study area when validated against the field-measured hydraulic conductivity. Likewise, Duan et al. (2012) evaluated the three existing PTFs (Campbell 1985; Saxton et al. 1986; Smettem and Bristow 1999) for the lawn soils of Texas and reported that these PTFs underestimated saturated hydraulic conductivity when compared to the field-measured hydraulic conductivity values measured at three cities of Texas with fully established grass. Similarly, Yao et al. (2015) conducted experiments in two coastal salt-affected farming areas in north Jiangsu Province, China. They assessed the predictability of 12 PTFs against lab-measured saturated hydraulic conductivity values and identified Ahuja and Vereecken PTFs as the best estimators for saturated hydraulic conductivity in the coastal reclamation farming area.

From the literature survey, it is revealed that fewer studies related to layer-wise hydraulic characterisation of lateritic vadose zones (Behera et al. 2003; Garg et al. 2005; Nandagiri et al. 2006) have been reported in the past. Also, it is obvious that no studies have been attempted for evaluating the performance of existing PTFs to estimate the saturated hydraulic conductivity of the lateritic vadose zones considering both location and depthwise variations. However, some studies have been conducted for deeper depths in specific soil types such as forest soils and sediments (e.g., Wagner et al. 2004; Puhlmann and von Wilpert 2012). Lateritic vadose zones, having typical characteristics, behave quite differently and hence significantly influence the groundwater recharge and transport processes. Laterites are prominent mainly within tropics of Cancer and Capricorn covering about one-third of the Earth's land area (Tardy 1997). In India, lateritic soils are found in Tamil Nadu, Andhra Pradesh, Odisha, West Bengal, and in Eastern and Western Ghats spreading over 248,000 $\mathrm{km}^{2}$ (Raychaudhuri 1980). Despite the importance and typical nature of lateritic vadose zones, very 
little information about the reliability of PTFs is available for the lateritic vadose zones. Needless to mention that such studies are of paramount importance for understanding the groundwater recharge (both natural and artificial) and contamination process through vadose zones. Although progress has been made in the development and use of PTFs to estimate soil hydraulic properties, in general, across the globe, to the best of our knowledge, there is little information on the assessment of PTFs for estimating the saturated hydraulic conductivity in the lateritic regions of eastern India. In this study, an attempt has been made to address some of the above-mentioned limitations of vadose-zone studies. To this end, the present study demonstrates the applicability and reliability of PTFs in estimating the hydraulic conductivity of vadose zone at different depths (beyond root-zone depth) and its spatial variation (from one location to another) under three different land management practices in a typical lateritic terrain of eastern India. Additionally, the basic physical properties of the vadose zone such as texture, bulk density and porosity were also determined as a function of depth and space. These findings of this study are very useful for better understanding of vadose-zone characteristics (both physical and hydraulic), which in turn can help in estimating the groundwater recharge and assessing groundwater vulnerability through the vadose zone.

\section{Methodology}

In the present study, three different locations were selected over the Experimental Farm of Agricultural \& Food Engineering (AgFE) Department, IIT Kharagpur (figure 1) located in West Medinipur district of West Bengal, India. The study sites are located in a gently sloping drainage basin at $22^{\circ} 19^{\prime} 10.97^{\prime \prime} \mathrm{N}$ latitude and $87^{\circ} 18^{\prime} 35.87^{\prime \prime} \mathrm{E}$ longitude, and an altitude of $48 \mathrm{~m}$ above mean sea level. The soil of the region is dominated by lateritic sandy loam with $0.65 \%$ of organic matter (Machiwal et al. 2006). This lateritic soil is rich in iron and aluminium, commonly found in hot and wet tropical areas.

\subsection{Investigation sites}

In this study, three investigation sites in the Experimental Farm were selected to represent three different land cover and management practices.
Of the three investigation sites, the first site (Site 1) is located in a bare plot, second site (Site 2) in a cultivated field $600 \mathrm{~m}$ away from the first site and the third site (Site 3) is located about $500 \mathrm{~m}$ away from the second site in the orchard area of Precision Farming Development Centre (figure 1). Vadose zone up to $2 \mathrm{~m}$ depth was considered at each site and the entire profile was divided into five layers, viz., $0-0.10,0.10-0.35,0.35-0.80,0.80-1.30$ and $1.30-1.70 \mathrm{~m}$. Different physical and hydraulic properties of the soil of the vadose zone were determined at different depths representing these five layers at all the three sites.

\subsection{Determination of physical properties}

Soil texture, bulk density and particle density of the five different layers were determined in the $2 \mathrm{~m}$ deep profile of the vadose zone by analysing undisturbed core samples collected from each of the layers of the three investigation sites. Bulk density was determined from the undisturbed core samples, and the particle density was determined by pycnometer method in the laboratory. Thereafter, the percentage of sand, silt and clay was determined by the standard method in the laboratory and all the soil samples were classified into different texture classes following the United States Department of Agriculture (USDA) soil texture classification system. Cross-sections of the vadose zone at the three sites under study are illustrated in figure 2 .

\subsection{Determination of saturated hydraulic conductivity}

\subsubsection{Measurement of field-saturated hydraulic conductivity}

Field-saturated hydraulic conductivity $\left(K_{\mathrm{fs}}\right)$ was determined by the Guelph Permeameter at all the three sites for the three layers $(0.10-0.35,0.35-0.80$ and $0.80-1.30 \mathrm{~m}$ ) of the vadose zone (figure $3 \mathrm{a}$ and $\mathrm{b}$ ). Guelph Permeameter is a constant-head borehole technique and it is based on the assumption of three-dimensional steady-state flow from a cylindrical, uncased test/auger hole in the unsaturated soil (Reynolds and Elrick 1985). It measures combined horizontal and vertical field-saturated hydraulic conductivity $\left(K_{\mathrm{fs}}\right)$ at specified depths by determining the steady-state flow rate $(Q)$ needed to maintain a constant depth of water in 


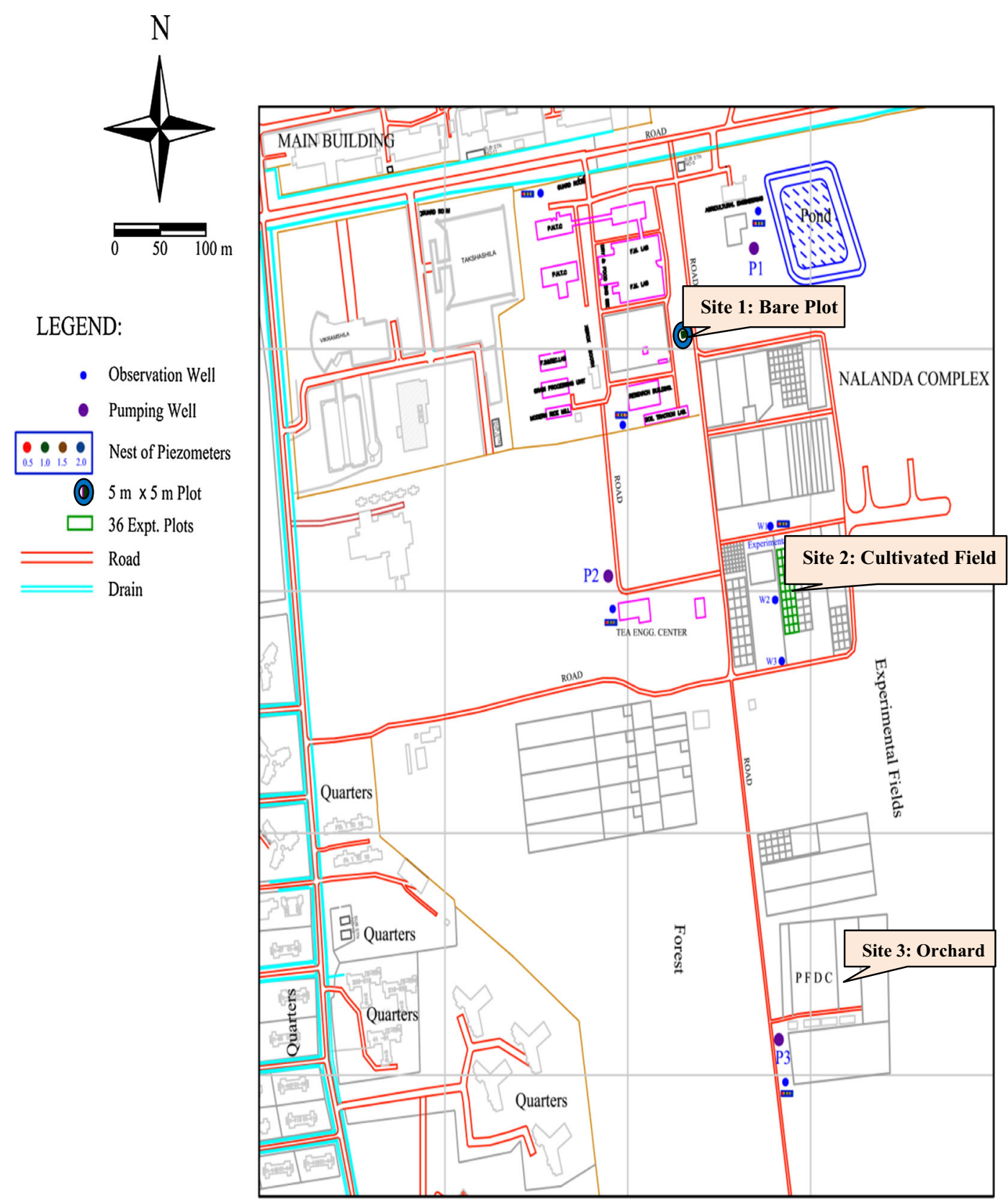

Figure 1. Location of the investigation sites.

the auger hole. In the present study, firstly the instrument was set at $20 \mathrm{~cm}$ depth to determine the hydraulic conductivity of the $0.1-0.35 \mathrm{~m}$ layer (figure 3a). The same auger hole was then excavated to the required depths in steps for measuring in-situ hydraulic conductivity in deeper layers (figure 3b). Great care was taken while preparing auger hole as it has a significant influence on hydraulic conductivity measurement (Bagarello 1997). At each depth, two sets of steady-state flow measurements were done for two constant heads (5 and $10 \mathrm{~cm}$ ) in the auger hole. During this experiment, steady-state flow rates were obtained after
5-6 hr of the test. Using the field data, $K_{\mathrm{fs}}$ was calculated for each layer by using the following equation (Elrick et al. 1989):

$$
K_{\mathrm{fs}}=\frac{C Q}{\left(2 \pi H^{2}+\pi a^{2} C+\left(2 \pi H / \alpha^{*}\right)\right)},
$$

where $Q$ is the constant discharge, $\left(\mathrm{L}^{3} \mathrm{~T}^{-1}\right) ; C$ is the shape coefficient which accounts for the interaction of capillarity and gravity in unsaturated flow; $H$ is the constant head maintained in the auger hole, $(L) ; a$ is the radius of the cylindrical auger hole, $(L)$; and $\alpha^{*}$ is the capillarity factor, $(1 / L)$. 


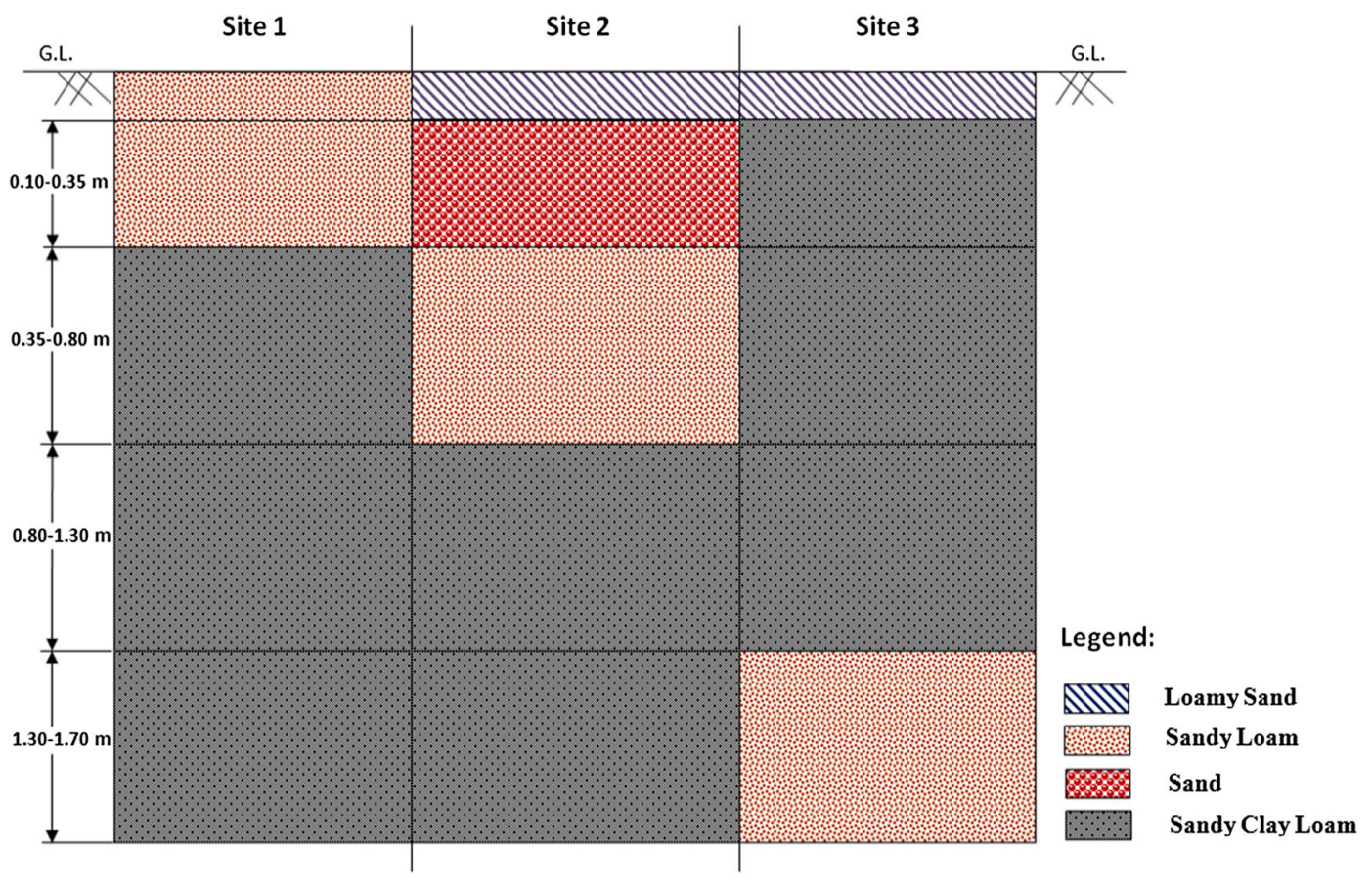

Figure 2. Cross-section of the vadose zone depicting five layers with their texture at the investigation sites.

The term field-saturated hydraulic conductivity is used mostly for field-measured hydraulic conductivity as the soil may not be fully saturated during measurements because of possible entrapped air within the soil pores. For this fact, the field-saturated hydraulic conductivity is generally lesser as compared to the saturated hydraulic conductivity. Therefore, the values of field-saturated hydraulic conductivity $\left(K_{\mathrm{fs}}\right)$ measured in the field were further converted into the corresponding saturated hydraulic conductivity (henceforth called measured $K_{\mathrm{s}}$ ) values by using a multiplying factor of 1.5 and 2.0 (Youngs 1968; Stephens et al. 1984; Reynolds and Elrick 1985).

\subsubsection{Estimation of saturated hydraulic conductivity by PTFs}

As the determination of saturated hydraulic conductivity $\left(K_{\mathrm{s}}\right)$ of soil is cumbersome and time consuming, they were estimated by using some well-known PTFs based on the availability of data in the study area. Thus, four PTFs were used in this study, namely Models 2 and 3 of Rosetta, Campbell method, and Rawls-Brakensiek or Cronican-Gribb (R-B/C-G) method.

Rosetta software uses a neural-network approach to estimate the values of soil hydraulic parameters.
The neural-network approach of Rosetta allows for the best possible prediction of hydraulic properties of a large number of samples within the model's database (Hermsmeyer et al. 2002; Cronican and Gribb 2004; Sander and Gerke 2007). Considering the availability of data, Models 2 (required inputs: sand, silt and clay) and 3 (required inputs: sand, silt, clay and bulk density) of Rosetta software were used to estimate the saturated hydraulic conductivity of the five vadose-zone layers at each site.

As the third PTF, the equation suggested by Campbell (1985) was employed for estimating the saturated hydraulic conductivity of the five layers for all the three sites taking clay and silt fractions as inputs. The Campbell equation is given as follows:

$$
K_{\mathrm{s}}=C \exp \left(-6.9 m_{\mathrm{c}}-3.7 m_{\mathrm{s}}\right)
$$

where $K_{\mathrm{s}}$ is the saturated hydraulic conductivity in $\mathrm{kg} \mathrm{s} / \mathrm{m}^{3}$, which is equal to $3.53 \times 10^{3} \mathrm{~cm} / \mathrm{h}, m_{\mathrm{c}}$ is the clay mass fractions, $m_{\mathrm{s}}$ is the silt mass fraction and $C$ is constant $\left(4 \times 10^{-3}\right)$.

Moreover, the fourth empirical equation used was the Rawls and Brakensiek (1989) regression equation (henceforth called ' $\mathrm{R}-\mathrm{B}$ method') that relates $K_{\mathrm{S}}$ to porosity $(n)$ of the soil sample, and percentage of sand and clay particles in the soil 
sample. This equation is expressed as

$$
K_{\mathrm{S}}=\exp \left[\begin{array}{l}
19.52348 n-8.96847-0.028212 C+0.00018107 S^{2}-0.0094125 C^{2} \\
-8.395215 n^{2}+0.077718 S n-0.00298 S^{2} n^{2}-0.019492 C^{2} n^{2} \\
+0.0000173 S^{2} C+0.02733 C^{2} n+0.001434 S^{2} n-0.0000035 C^{2} S
\end{array}\right],
$$

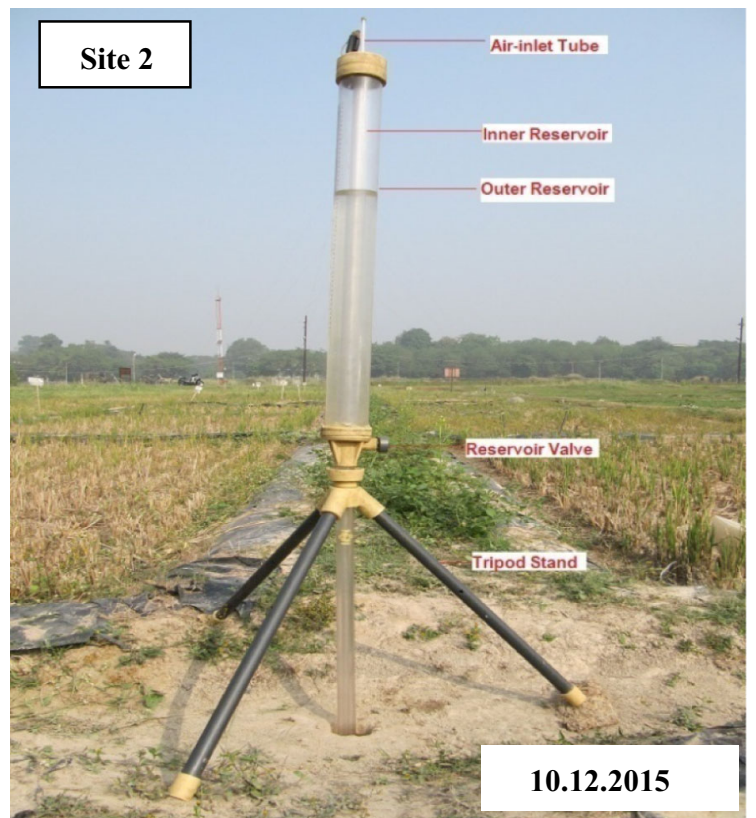

(a)

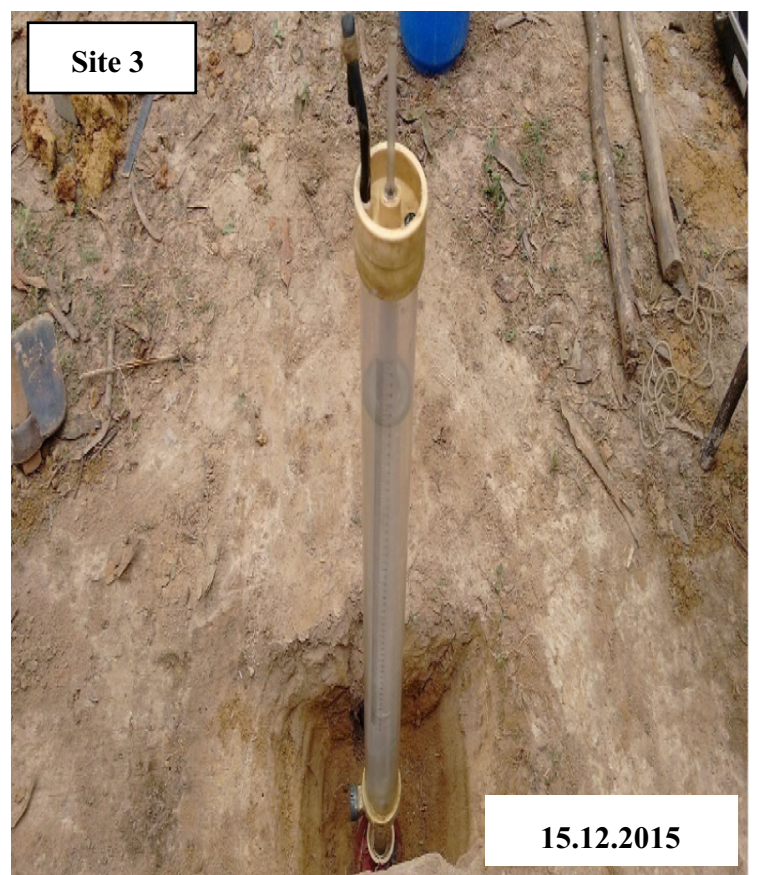

(b)

Figure 3. (a) Guelph Permeameter installed at a shallow depth. (b) Guelph Permeameter installed at a deeper depth. where $K_{\mathrm{S}}$ is the saturated hydraulic conductivity $(\mathrm{cm} / \mathrm{h})$ of the soil sample, $n$ is the porosity expressed in fraction, $C$ is the clay percentage in the sample and $S$ is the sand percentage in the sample.

It should be noted that equation (3) is valid for soils with 5-70\% sand-sized particles and 5$60 \%$ clay-sized particles. However, at some depths of the study sites, there exists greater sand percentage. For such samples, the equation developed by Cronican and Gribb (2004) was applied. This equation gives better results for sandy soils having $>70 \%$ sand than Model 2 of Rosetta and equation (3). The Cronican and Gribb's equation (henceforth called ' $\mathrm{C}-\mathrm{G}$ method') is given as

$$
\begin{aligned}
K_{\mathrm{s}}= & \exp (99.49815337-2.808839211 S \\
& +0.017873264 S^{2}-0.019881556 S C \\
& \left.+0.000268919 S^{2} C\right)
\end{aligned}
$$

where $K_{\mathrm{S}}$ is in $\mathrm{cm} / \mathrm{s}$. In this study, equation (4) was used for the vadose-zone samples of three locations having sand percentage greater than $70 \%$.

\subsection{Evaluation of pedotransfer functions}

The values of saturated hydraulic conductivity $\left(K_{\mathrm{s}}\right)$ estimated by equations $(2-4)$ as well as Models 2 and 3 of Rosetta were compared with the corresponding values of in-situ hydraulic conductivity. The performance of the four PTFs used in this study was evaluated using five statistical indicators namely, bias, mean absolute error (MAE), root mean square error (RMSE), geometric mean error ratio (GMER) and geometric standard deviation of the error ratio (GSDER) together with graphical indicators such as simultaneous plots of measured and estimated hydraulic conductivity values and 1:1 plot. A brief description of these statistical indicators is given below.

The performance of the models was assessed by comparing the bias in the predictions of $K_{\mathrm{s}}$ in each layer for three sites with the respective measured field-saturated hydraulic conductivity data by using the following formula:

$$
\operatorname{Bias}=\left(K_{m i}-K_{p i}\right),
$$


where $K_{m i}$ is the measured value of the fieldsaturated hydraulic conductivity in the $i$ th layer and $K_{p i}$ is the predicted value of the saturated hydraulic conductivity in the $i$ th layer.

For evaluating the overall performance of the models, statistical indicators such as MAE and RMSE as well as GMER and GSDER were used. The expressions of MAE and RMSE are:

$$
\begin{aligned}
\mathrm{MAE} & =\frac{1}{n} \sum_{i=1}^{n}\left|K_{m i}-K_{p i}\right|, \\
\mathrm{RMSE} & =\sqrt{\frac{1}{n} \sum_{i=1}^{n}\left(K_{m i}-K_{p i}\right)^{2} .}
\end{aligned}
$$

GMER and GSDER are special statistical indicators for the parameters such as hydraulic conductivity values, which are log-normally distributed. They are calculated based on the error ratio $(\varepsilon)$, which is defined as the ratio of predicted hydraulic conductivity $\left(K_{\mathrm{p}}\right)$ to measured hydraulic conductivity $\left(K_{\mathrm{m}}\right)$ [equation 8]. These indicators GMER and GSDER are calculated using equations (9) and (10), respectively (Tietje and Hennings 1996; Wagner et al. 2001):

$$
\begin{aligned}
\varepsilon & =\frac{K_{\mathrm{p}}}{K_{\mathrm{m}}} \\
\text { GMER } & =\exp \left(\frac{1}{n} \sum_{i=1}^{n} \ln \left(\varepsilon_{i}\right)\right), \\
\text { GSDER }= & \exp \left[\left(\frac { 1 } { n - 1 } \sum _ { i = 1 } ^ { n } \left[\ln \left(\varepsilon_{i}\right)\right.\right.\right. \\
& \left.\left.-\ln (\text { GMER })]^{2}\right)^{1 / 2}\right] .
\end{aligned}
$$

The GMER value equals to 1 corresponds to an exact matching between the measured and predicted data; GMER $<1$ indicates that the predicted values are underestimated, while GMER > 1 indicates a general over prediction. On the other hand, the GSDER equals to 1 corresponds to a perfect match and it grows with deviation from the measured data. Thus, the best performing model will have GMER value close to 1 and a small value of GSDER.

In addition to the afore-mentioned statistical indicators, graphical indicators such as 1:1 plot and simultaneous plots of the measured and estimated saturated hydraulic conductivity values with respect to depth and location were also plotted to evaluate the performance of four PTFs.

\subsection{Estimation of unsaturated hydraulic conductivity}

Unsaturated hydraulic conductivity, $K(\theta)$, of the bare plot was evaluated from the water retention function, saturated hydraulic conductivity $\left(K_{\mathrm{s}}\right)$ and the soil hydraulic parameters predicted by Rosetta using measured bulk density and particle size, which is well known as the van GenuchtenMualem model, and given as

$K_{\mathrm{u}}=K\left(S_{\mathrm{e}}\right)=K_{0} S_{\mathrm{e}}^{L}\left\{1-\left[1-S_{\mathrm{e}}^{n /(n-1)}\right]^{1-(1 / n)}\right\}^{2}$,

wherein $S_{\mathrm{e}}$ is given as

$$
S_{\mathrm{e}}=\frac{\theta(h)-\theta_{\mathrm{r}}}{\theta_{\mathrm{s}}-\theta_{\mathrm{r}}}=\frac{1}{\left[1+(\alpha h)^{n}\right]^{1-(1 / n)}},
$$

where $\theta(h)$ is the volumetric water content as a function of soil suction $(h)\left(\mathrm{cm}^{3} / \mathrm{cm}^{3}\right), \theta_{\mathrm{r}}$ is the residual water content $\left(\mathrm{cm}^{3} / \mathrm{cm}^{3}\right), \theta_{\mathrm{s}}$ is the saturated water content $\left(\mathrm{cm}^{3} / \mathrm{cm}^{3}\right), \alpha$ is the van Genuchten parameter related to the inverse of the air-entry pressure, $n$ is the a measure of the pore-size distribution, $h$ is the the soil-water pressure head (i.e., soil suction) $(\mathrm{cm}), K_{0}$ is the fitted matching point at saturation (cm/day), $S_{\mathrm{e}}$ is the relative saturation and $L$ is the empirical parameter.

\section{Results and discussion}

\subsection{Soil physical properties of the vadose zone}

The results of the texture analysis, bulk density and porosity determined for the five vadose-zone layers over the three study sites are summarised in table 1. It is apparent that mainly two types of soil textures (sandy loam and sandy clay loam) are dominant up to $1.7 \mathrm{~m}$ deep vadose zone of the study area, though there is a considerable variation of sand, silt and clay particles at individual depths of all the locations. Also, it is evident that the highest percentage of sand can be seen in all the layers at Site 2 as compared to the respective layers of other sites. On the other hand, greatest silt percentage can be seen at Site 1 up to 1.3 $\mathrm{m}$ depth, whereas greatest clay percentage occurs 
Table 1. Physical properties of five vadose-zone layers at three study sites.

\begin{tabular}{|c|c|c|c|c|c|}
\hline \multirow[b]{2}{*}{ Description } & \multicolumn{5}{|c|}{ Values of different vadose-zone layers } \\
\hline & $0-0.10 \mathrm{~m}$ & $0.10-0.35 \mathrm{~m}$ & $0.35-0.80 \mathrm{~m}$ & $0.80-1.30 \mathrm{~m}$ & $1.30-1.70 \mathrm{~m}$ \\
\hline \multicolumn{6}{|l|}{ Site 1: Bare plot } \\
\hline Sand $(\%)$ & 67.00 & 70.00 & 53.00 & 53.00 & 52.00 \\
\hline Silt (\%) & 17.40 & 14.40 & 21.65 & 19.70 & 16.80 \\
\hline Clay $(\%)$ & 15.60 & 15.60 & 25.35 & 27.30 & 31.20 \\
\hline Texture & Sandy loam & Sandy loam & Sandy clay loam & Sandy clay loam & Sandy clay loam \\
\hline Bulk density $\left(\mathrm{g} / \mathrm{cm}^{3}\right)$ & 1.724 & 1.920 & 1.828 & 1.653 & 1.833 \\
\hline Porosity (\%) & 25.76 & 19.22 & 22.29 & 33.28 & 24.22 \\
\hline \multicolumn{6}{|c|}{ Site 2: Cultivated plot } \\
\hline Sand $(\%)$ & 88.01 & 92.01 & 82.03 & 74.01 & 66.10 \\
\hline Silt (\%) & 4.00 & 2.00 & 2.00 & 6.00 & 9.97 \\
\hline Clay (\%) & 7.99 & 5.99 & 15.98 & 19.99 & 23.93 \\
\hline Texture & Loamy sand & Sandy & Sandy loam & Sandy clay loam & Sandy clay loam \\
\hline Bulk density $\left(\mathrm{g} / \mathrm{cm}^{3}\right)$ & 1.992 & 1.739 & 1.694 & 1.821 & 1.910 \\
\hline Porosity (\%) & 23.87 & 32.02 & 34.48 & 26.76 & 25.20 \\
\hline \multicolumn{6}{|l|}{ Site 3: Orchard } \\
\hline Sand (\%) & 86.01 & 70.01 & 66.00 & 62.00 & 56.13 \\
\hline Silt (\%) & 8.00 & 10.00 & 14.00 & 6.00 & 25.92 \\
\hline Clay (\%) & 6.00 & 19.99 & 20.00 & 32.00 & 17.95 \\
\hline Texture & Loamy sand & Sandy clay loam & Sandy clay loam & Sandy clay loam & Sandy loam \\
\hline Bulk density $\left(\mathrm{g} / \mathrm{cm}^{3}\right)$ & 1.979 & 1.964 & 1.728 & 1.756 & 1.813 \\
\hline Porosity (\%) & 24.60 & 24.21 & 33.61 & 32.62 & 28.98 \\
\hline
\end{tabular}

in three vadose-zone layers $(0-0.10,0.35-0.80$ and $1.30-1.70 \mathrm{~m}$ ) at Site 1.

As far as the variation of bulk density with depth is concerned, a usual trend of increasing bulk density is apparent in the deeper layers (0.35-0.80, 0.80-1.30 and $1.30-1.70 \mathrm{~m})$ at Sites 2 and 3 (table 1). Exceptionally higher values of bulk density at shallow depths could be attributed to the local high compaction of the soil, whereas the existence of loosely packed soil layer or micro-pores could be the reason for relatively low bulk density values at deeper depths. Although the spatial variations of bulk density with depth and location are practically appreciable except at some depths (e.g., $0.1-0.35$ and $0.35-0.80 \mathrm{~m}$ layers at Site 2, $0-0.10$ and $0.10-0.35 \mathrm{~m}$ layers, $0.35-0.80$ and 1.30 $1.70 \mathrm{~m}$ layer of Site 3 ) as well as at some locations (e.g., Sites 2 and 3 in $0-10$ and $0.35-0.80 \mathrm{~m}$ layers, Sites 3 and 1 in $0.10-0.35$ and $1.30-1.70$ m layers), they were not found to be statistically significant.

As far as the depth-wise variation of the bulk density of the vadose zone is concerned, at Site 1 it varies from $1.653 \mathrm{~g} / \mathrm{cm}^{3}(0.80-1.30 \mathrm{~m}$ layer $)$ to $1.920 \mathrm{~g} / \mathrm{cm}^{3}(0.10-0.35 \mathrm{~m}$ layer $)$, from $1.694 \mathrm{~g} / \mathrm{cm}^{3}$ $(0.35-0.80 \mathrm{~m}$ layer $)$ to $1.992 \mathrm{~g} / \mathrm{cm}^{3}(0-0.10 \mathrm{~m}$ layer) at Site 2 and from $1.728 \mathrm{~g} / \mathrm{cm}^{3}(0.35-0.80 \mathrm{~m}$ layer) to $1.979 \mathrm{~g} / \mathrm{cm}^{3}(0-0.10 \mathrm{~m}$ layer $)$ at Site 3 .
The second layer $(0.10-0.35 \mathrm{~m})$ of Site 1 and the first layer $(0-0.10 \mathrm{~m})$ of Site 2 are the most compacted layers, whereas both second $(0-0.10 \mathrm{~m})$ and third $(0.10-0.35 \mathrm{~m})$ layers are highly compacted at Site 3. The unusual compaction of shallow layers is attributed to local compaction and the type of land use.

On the other hand, physical property such as the porosity of the vadose zone shows little variation at some depths for all the sites (table 1). However, the range of porosity is from $19.22 \%(0.10-0.35$ $\mathrm{m}$ layer $)$ to $33.28 \%(0.80-1.30 \mathrm{~m}$ layer $)$ at Site 1 , $23.87 \%$ (0-0.10 m layer) to $34.48 \%(0.35-0.80 \mathrm{~m}$ layer) at Site 2 and $24.21 \%(0.10-0.35 \mathrm{~m}$ layer $)$ to $33.61 \%(0.35-0.80 \mathrm{~m}$ layer $)$ at Site 3 . These variations of porosity are in agreement with the variation of texture and compaction level.

\subsection{Saturated hydraulic conductivity}

\subsubsection{In-situ hydraulic conductivity of the vadose zone}

Variation in the values of field-measured hydraulic conductivity $\left(K_{\mathrm{fs}}\right)$ with depth and location is illustrated in figure 4 . It is apparent from figure 4 and table 2 that the $K_{\mathrm{fs}}$ values range from 0.39 to 6.77 


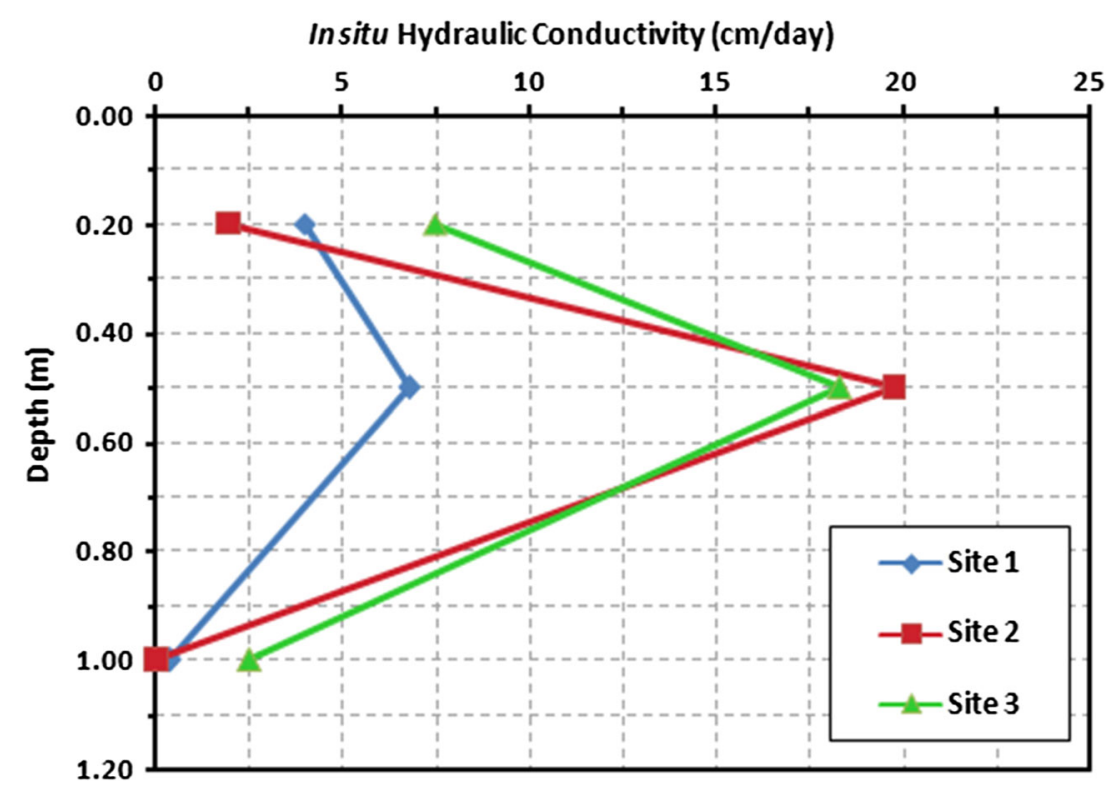

Figure 4. Variation of in-situ hydraulic conductivity $\left(K_{\mathrm{fs}}\right)$ with depth and locations.

$\mathrm{cm} /$ day for the barren land, 0.031 to $19.79 \mathrm{~cm} /$ day for the cultivated land and 2.52 to $18.32 \mathrm{~cm} /$ day for the orchard area. Relatively higher values of the field-saturated hydraulic conductivity obtained in the orchard area may be due to the presence of deeper roots of horticultural plants in the vadose zone. It is interesting to note that despite the slightly higher bulk density of the $0.10-0.35 \mathrm{~m}$ layer in the barren land, a higher value of field-saturated hydraulic conductivity value is found in this layer, which could be attributed to localised effects such as the presence of macro-pores and their continuity. Although the variation in the $K_{\mathrm{fs}}$ of the study area due to different land uses is not statistically significant at $5 \%$ level of significance, the mean values of $K_{\mathrm{fs}}$ in the barren (mean $K_{\mathrm{fs}}=3.72 \mathrm{~cm} /$ day), cultivated (mean $K_{\mathrm{fs}}=7.26 \mathrm{~cm} /$ day) and orchard (mean $K_{\mathrm{fs}}=9.45 \mathrm{~cm} /$ day) lands vary considerably from the practical viewpoint. In contrast, the depth-wise variation of $K_{\mathrm{fs}}$ in the study area was found to be statistically significant at $5 \%$ level of significance. It is obvious from table 2 that in the 0.10-0.35 m layer, the values of in-situ hydraulic conductivity range from 1.97 (Site 2) to $7.5 \mathrm{~cm} /$ day (Site 3), while they vary from 6.77 (Site 1) to 19.79 $\mathrm{cm} /$ day (Site 2) in the 0.35-0.8 m layer. The insitu hydraulic conductivity of the $0.8-1.30 \mathrm{~m}$ layer varies from 0.031 (Site 2) to $2.52 \mathrm{~cm} /$ day (Site 3 ). Thus, the $0.35-0.8 \mathrm{~m}$ layer has the highest hydraulic conductivity and the deepest layer (0.8$1.30 \mathrm{~m}$ ) has the lowest hydraulic conductivity with intermediate values in the $0.10-0.35 \mathrm{~m}$ layer. This trend is visible at all the sites under study, thereby suggesting the presence of relatively low permeable layers at deeper depths. This has been confirmed from the field investigation that hard laterites are more prominent at deeper depths (beyond $0.8 \mathrm{~m}$ below the ground surface) in the study area.

As far as the field-saturated hydraulic conductivity values of various textural classes in the study area are concerned, it varies from 4 to 19.79 $\mathrm{cm} /$ day for the sandy loam, 0.031 to $18.32 \mathrm{~cm} /$ day for the sandy clay loam and $1.96 \mathrm{~cm} /$ day for the sandy soils. It is evident that despite having similar textured vadose-zone layers at the three locations (Sites 1-3), the variability of $K_{\mathrm{fs}}$ values in the same vadose-zone layers suggests more dependence of saturated hydraulic conductivity on other factors such as soil structure, bulk density, arrangement of particles, etc. Moreover, a comparison of the results of the study area with past studies also revealed that the saturated hydraulic conductivity values of similar textured soils vary significantly from the corresponding $K_{\mathrm{fs}}$ values obtained in this study. For example, in Fengqiu County, North China, Li et al. (2007) reported the values of in-situ saturated hydraulic conductivity for sandy loam and sandy soils to be 9.85 and $45.21 \mathrm{~cm} /$ day, respectively. In another study, Shin et al. (2012) found that the values of labmeasured saturated hydraulic conductivity range from 65.84 to $186.19 \mathrm{~cm} /$ day for sandy loam soils of Little Washita watershed in Oklahoma. Seki et al. (2015) reported the lab-measured hydraulic conductivity values to be $1132 \mathrm{~cm} /$ day for sand and $83 \mathrm{~cm} /$ day for sandy loam soil layer in Borneo 


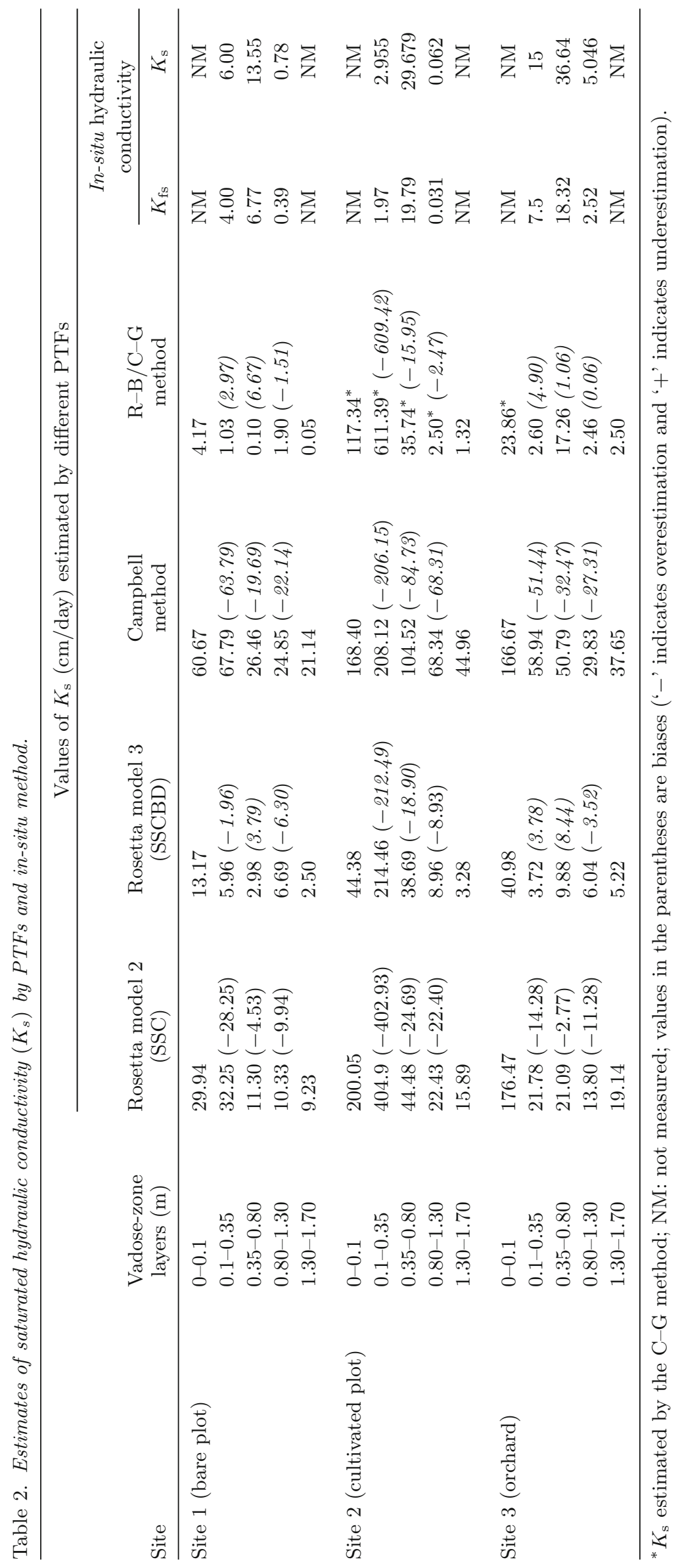


Island of Indonesia. This clearly indicates the typical hydraulic characteristics of lateritic vadose zones.

\subsubsection{Performance of the PTFs}

(1) Depth-wise performance: Comparisons of depthwise values of saturated hydraulic conductivity obtained by the four empirical methods/PTFs for the three sites with those measured in the field $\left(K_{\mathrm{fs}}\right)$ are shown in table 2 and figure $5(\mathrm{a}-\mathrm{c})$. Among the empirical methods, the Campbell method monotonically overestimates $K_{\mathrm{s}}$ for all the depths and locations (figure $5 \mathrm{a}-\mathrm{c}$ ). In the $0.10-0.35 \mathrm{~m}$ layer, it overestimates $K_{\mathrm{S}}$ by 8 100 times with the bias ranging from -51.44 to $-206.15 \mathrm{~cm} /$ day (table 2). Similarly, in the 0.35 $0.8 \mathrm{~m}$ layer, it estimates $K_{\mathrm{s}}$ three to five folds greater than the corresponding measured values (bias varying from -32.47 to $-84.73 \mathrm{~cm} /$ day), whereas in the deeper layer $(0.8-1.30 \mathrm{~m}), K_{\mathrm{s}}$ is overestimated by $12-1000$ times (bias varying from -27.31 to $-68.31 \mathrm{~cm} /$ day). Further, when compared with the measured $K_{\mathrm{s}}$, in the $0.10-0.35 \mathrm{~m}$ layer, overestimation is by $4-70$ times with the bias ranging from -43.9 to $-205.2 \mathrm{~cm} /$ day. Similarly, in the $0.35-0.8 \mathrm{~m}$ layer, it estimates $K_{\mathrm{s}}$ one to four folds greater than the measured values (bias varying from -12.9 to $-74.8 \mathrm{~cm} /$ day), while $K_{\mathrm{s}}$ is overestimated by $6-1000$ times in the deeper layer $(0.8-1.30 \mathrm{~m})$ with bias values varying from -24.1 to $-68.3 \mathrm{~cm} /$ day. The general over-predictability of the Campbell method in this study is in contrast with those reported by Wagner et al. (2001) and Duan et al. (2012).

Like the Campbell method, Model 2 of Rosetta overestimates the values of saturated hydraulic conductivity at all the depths for all the sites under study but in a smaller range. In the 0.10-0.35 $\mathrm{m}$ layer, the model prediction varies from three times with a bias of $-14.28 \mathrm{~cm} /$ day (Site 3 ) to 200 times with a bias of $-402.93 \mathrm{~cm} /$ day (Site 2). In the next layer, model moderately over predicts $K_{\mathrm{S}}$ with the lowest over prediction (about one fold) at Site 3 and the highest over prediction (about two folds) at Site 2. In the deeper layer $(0.8-1.3 \mathrm{~m})$, the model prediction varies from 5 times at Site 3 (bias $=-11.28 \mathrm{~cm} /$ day) to 700 times at Site 2 (bias $=-22.4 \mathrm{~cm} /$ day). However, when compared with the measured $K_{\mathrm{s}}$ values, Model 2 underestimates at two sites (table 2). In the shallow layer, the model prediction varies from 2 times with bias of $-6.78 \mathrm{~cm} /$ day (Site 3 ) to 100 times with bias
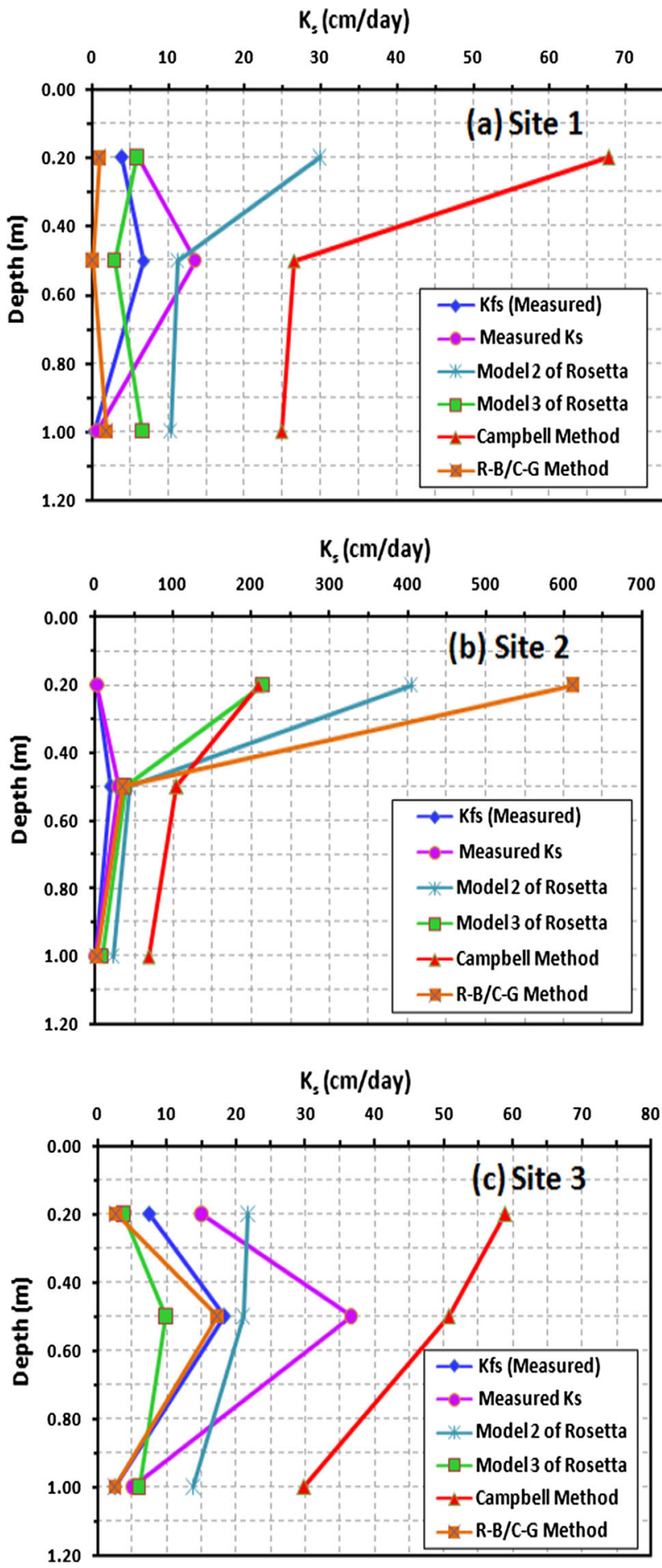

Figure 5. (a-c) Comparison of $K_{\mathrm{s}}$ estimated by the PTFs with in-situ hydraulic conductivity $\left(K_{\mathrm{fs}}\right)$ and measured $K_{\mathrm{s}}$ for: (a) Site 1; (b) Site 2; and (c) Site 3.

of $-401.95 \mathrm{~cm} /$ day (Site 2). In the intermediate layer, the model over predicts $K_{\mathrm{s}}$ by two times only at Site 2 (bias $=-14.8 \mathrm{~cm} /$ day), while the lowest under prediction is within one order of magnitude with a difference of only $2.25 \mathrm{~cm} /$ day at Site 1 . 
In the $0.8-1.3 \mathrm{~m}$ layer, the model over prediction varies from 3 times at Site 3 (bias $=-8.8 \mathrm{~cm} /$ day) to 300 times at Site 2 (bias $=-22.4 \mathrm{~cm} /$ day).

The $\mathrm{R}-\mathrm{B} / \mathrm{C}-\mathrm{G}$ method yields $K_{\mathrm{s}}$ values mostly with low bias when compared with both $K_{\mathrm{fs}}$ and measured $K_{\mathrm{S}}$ (table 2). It is apparent from table 2 and figure $5(\mathrm{a}-\mathrm{c})$ that in the $0.10-0.35 \mathrm{~m}$ layer, the $\mathrm{R}-\mathrm{B} / \mathrm{C}-\mathrm{G}$ method underestimates $K_{\mathrm{s}}$ values by three (Site 3 ) to four times (Site 1) with a lower bias $(<5 \mathrm{~cm} /$ day $)$ except for Site 2 where it yields exceptionally high value of $K_{\mathrm{s}}(611.39 \mathrm{~cm} /$ day $) . \mathrm{In}$ the $0.35-0.8 \mathrm{~m}$ layer, it underestimates $K_{\mathrm{s}}$ at Sites 1 and 3 (the value of $K_{\mathrm{s}}$ at Site 3 is slightly less than the measured one), whereas it overestimates by about two times at Site 2 with a bias of -15.95 $\mathrm{cm} /$ day. Finally, in the deeper layer, this method overestimates $K_{\mathrm{s}}$ with a bias of $-1.51 \mathrm{~cm} /$ day by about 5 times (Site 1) to about 80 times (Site 2) with a bias of $-2.47 \mathrm{~cm} /$ day, whereas it yields $K_{\mathrm{s}}$ values closer to the measured one at Site 3 . It is also obvious from table 2 that when compared with the measured $K_{\mathrm{s}}$ values, the $\mathrm{R}-\mathrm{B} / \mathrm{C}-\mathrm{G}$ method predicts in a similar way as with the $K_{\mathrm{fs}}$ value.

Moreover, $K_{\mathrm{S}}$ value in $0.10-0.35 \mathrm{~m}$ layer estimated by Model 3 of Rosetta was found to be within one order of magnitude at Site 1 (bias = $-1.96 \mathrm{~cm} /$ day), but it is overestimated by about 2 times at Site 3 (bias $=3.78 \mathrm{~cm} /$ day) to 100 times at Site 2 (bias $=-212.5 \mathrm{~cm} /$ day). However, in the intermediate layer (0.35-0.8 m layer), it underestimates $K_{\mathrm{S}}$ values by two folds at Sites 1 (bias $=$ $3.79 \mathrm{~cm} /$ day) and 3 (bias $=8.44 \mathrm{~cm} /$ day)], while $K_{\mathrm{s}}$ values are overestimated by approximately two times (bias $=-18.9 \mathrm{~cm} /$ day) at Site 2 . In contrast, in the deeper layer $(0.8-1.30 \mathrm{~m})$, it overestimates $K_{\mathrm{S}}$ values at all the locations with bias values ranging from -3.52 (Site 3 ) to $-8.93 \mathrm{~cm} /$ day (Site 2). A comparison of the model prediction with the measured $K_{\mathrm{s}}$ values reveals that the prediction pattern remains similar in all the layers except the shallow layer $(0.10-0.35 \mathrm{~m})$ of Site 1 where the model predicted $K_{\mathrm{s}}$ is almost equal to the measured $K_{\mathrm{s}}$ (bias $=0.04 \mathrm{~cm} /$ day).

Based on the above results and discussion, it can be inferred that when the estimated hydraulic conductivity values are compared with the fieldsaturated hydraulic conductivity $\left(K_{\mathrm{fs}}\right)$, the $\mathrm{R}-\mathrm{B} /$ C- $\mathrm{G}$ method generally performs somewhat better in estimating $K_{\mathrm{s}}$ of the deeper and intermediate layers where sandy clay loam type soil is prominent. In general, Model 3 of Rosetta estimates relatively closer $K_{\mathrm{s}}$ values than other PTFs, specifically for coarse-textured soils when compared to both measured $K_{\mathrm{fs}}$ and $K_{\mathrm{s}}$ values. In contrast to that, Minasny and McBratney (2000) reported Model 3 of Rosetta giving best results for finer clayey soils of Australia. However, Sobieraj et al. (2001) reported Model 3 of Rosetta to be the best performing PTF for a tropical rainforest area of Peru dominated by sandy loam and loam type textures. Interestingly, all the PTFs yield highly overestimated values with very large errors in $K_{\mathrm{s}}$ estimates in the $0.10-0.35$ $\mathrm{m}$ layer of Site 2 (soil texture: sandy). Also, all the PTFs predict $K_{\mathrm{s}}$ values with very high values of errors at all the layers of Site 2, where the higher sand percentages $(>70 \%)$ are evident than other two sites. This finding indicates that all of the PTFs completely fail to represent the fieldsaturated hydraulic conductivity of lateritic vadose zone having a higher sand percentage.

(2) Overall performance of the PTFs: In order to evaluate the overall performance of the PTFs for this lateritic terrain, salient global statistical indices were calculated using the entire data set and their values are summarised in table 3 . It is obvious from the table that all the methods overestimate the values of saturated hydraulic conductivity as indicated by the GMER values exceeding 1. Based on the GMER values, the $\mathrm{R}-\mathrm{B} / \mathrm{C}-\mathrm{G}$ method performs comparatively well with the GMER value of 1.86 followed by Model 3 of Rosetta (GMER = 4.24) when compared with the field-saturated hydraulic conductivity $\left(K_{\mathrm{fs}}\right)$. However, Model 2 of Rosetta and the Campbell method poorly predicts the saturated hydraulic conductivity with GMER values of 10.91 and 22.26, respectively. In contrast, the performances of the PTFs are somewhat improved when their results are compared with the measured $K_{\mathrm{s}}$ values as indicated by decreased GMER and error values with some exceptions (table 3 ). In this case also, the $\mathrm{R}-\mathrm{B} / \mathrm{C}-\mathrm{G}$ method estimates the saturated hydraulic conductivity values best fit with the measured $K_{\mathrm{s}}$ values with GMER almost equal to 1 followed by Model 3 (GMER = 2.33). The GSDER values for the four PTFs, when compared with the measured $K_{\mathrm{s}}$ values, vary over a range from 8.27 to 19.71 . Except for the $\mathrm{R}-\mathrm{B} / \mathrm{C}-\mathrm{G}$ method, all the other PTFs have almost closer GSDER values. Surprisingly, the PTF with the least GMER has the highest GSDER value. On the other hand, Model 3 of Rosetta, which has the second least GMER value equal to 2.33, has a GSDER of 11.17. Also, the values of MAE and RMSE are the lowest for Model 3 (MAE $=31.66 \mathrm{~cm} /$ day; 
Table 3. Goodness-of-fit statistics for the PTFs.

\begin{tabular}{lllll}
\hline & $\begin{array}{c}\text { MAE } \\
\text { PTFs }\end{array}$ & $\begin{array}{c}\text { RMSE } \\
(\mathrm{cm} / \text { day })\end{array}$ & GMER & GSDER \\
\hline 1. Rosetta model 2 (SSC) & 57.89 & 135.28 & 10.91 & 9.46 \\
& $(56.47)$ & $(134.75)$ & $(6)$ & $(9.66)$ \\
2. Rosetta model 3 (SSCBD) & 29.79 & 71.35 & 4.24 & 11.09 \\
& $(31.66)$ & $(71.4)$ & $(2.33)$ & $(11.17)$ \\
3. Campbell method & 64.26 & 84.17 & 22.26 & 8.26 \\
& $(58.88)$ & $(81.42)$ & $(12.25)$ & $(8.27)$ \\
4. R-B/C-G method & 71.66 & 203.27 & 1.86 & 20.22 \\
& $(74.54)$ & $(203.03)$ & $(1.02)$ & $(19.71)$
\end{tabular}

$\overline{\text { Values in parentheses indicate the error values when compared with the measured } K_{\mathrm{s}}}$ values.
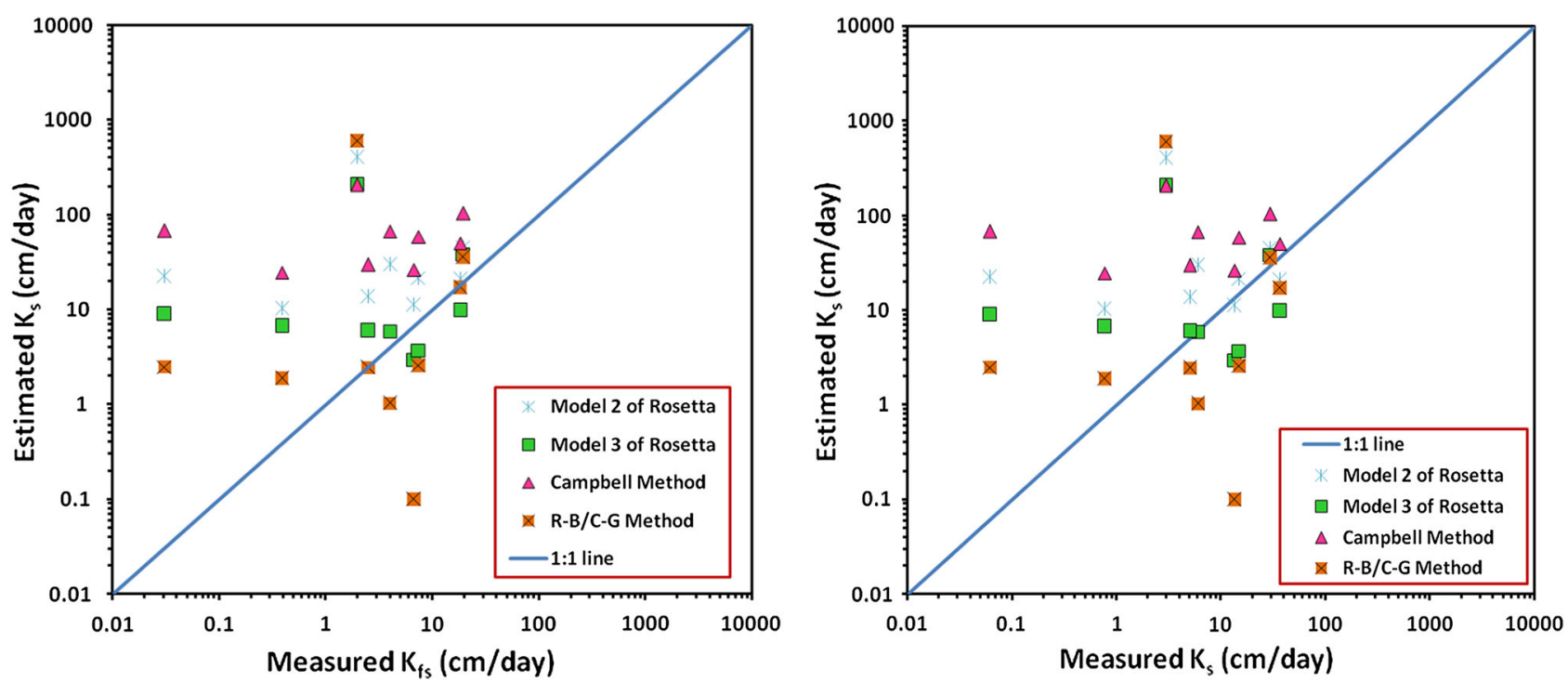

Figure 6. 1:1 plot for comparison of in-situ measured hydraulic conductivity $\left(K_{\mathrm{fs}}\right.$ and $\left.K_{\mathrm{s}}\right)$ with the saturated hydraulic conductivity values estimated by the PTFs.

RMSE $=71.4 \mathrm{~cm} /$ day) and the greatest for the $\mathrm{R}-\mathrm{B} / \mathrm{C}-\mathrm{G}$ method $(\mathrm{MAE}=74.54 \mathrm{~cm} /$ day; RMSE $=203.03 \mathrm{~cm} /$ day). Overall, the Campbell method tends to over-predict all the $K_{\mathrm{s}}$ values as shown in figures 5 and 6 . Although it is difficult to conclude the best performing PTF from the graphical indicator i.e., 1:1 plot (figure 6) due to smaller data sets, based on the statistical indicators, it can be concluded that Model 3 of Rosetta provides better estimates of saturated hydraulic conductivity in the study area to some extent. The larger errors associated with the $K_{\mathrm{s}}$ estimated by the PTFs are due to the fact that the saturated hydraulic conductivity depends more on soil structural properties than the soil texture. Empirical nature of the PTFs as well as use of data sets from completely different geographic locations and climatic settings may contribute to the larger error values when compared with the actual field data.

\subsubsection{Limitations of the PTFs}

Although some empirical models/PTFs provide successful approximations of the difficult-tomeasure soil hydraulic properties to some extent, they are sometimes problematic and pose larger uncertainties. These larger uncertainties in the results of PTFs may arise because of several factors: inherent variability of the saturated hydraulic conductivity itself due to methods of measurement, representative sample volume, measurement error or its spatial variability (Minasny and McBratney 2000). The accuracy of some PTFs highly depends 


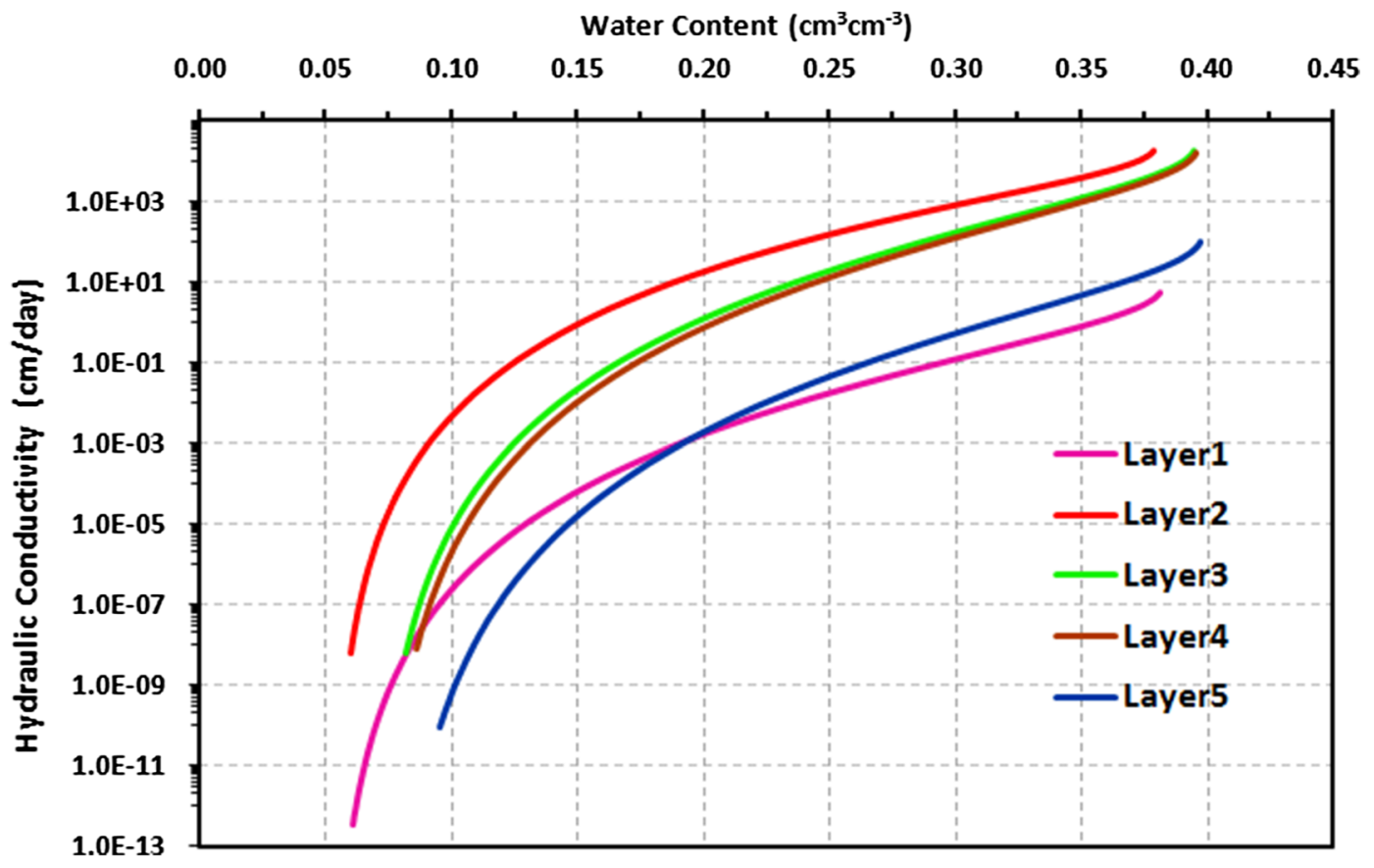

Figure 7. Variation of unsaturated hydraulic conductivity, $K(\theta)$, in five vadose-zone layers of bare plot.

upon the quality of input data. For instance, the particle-size distributions should be as detailed as possible for the Campbell model (Campbell $1985)$ as the information about only three fractions (sand, silt and clay) may result in the reduction of its performance (Wagner et al. 2001; Manyame et al. 2007). Moreover, the results of this study as well as past studies highlight the limitations of PTFs' applicability in the regions having different climatic settings, hydrologic conditions and data availability. Thus, the performance of the PTFs used in this study is limited to the lateritic soils as well as other locations having similar soils, hydro-climatic conditions and land management practices. Nevertheless, all of the PTFs used in this study can be applied to other locations/terrains for examining their performances considering location-specific calibrations, if possible.

\subsection{Unsaturated hydraulic conductivity}

Unsaturated hydraulic conductivity depends not only on soil moisture content, but also on the number, size and continuity of the soil pores. The unsaturated hydraulic conductivity, $K(\theta)$, curves obtained for the five vadose-zone layers of the bare plot are shown in figure 7 . The wetter the soil, the greater is the conductivity of the soil. The hydraulic conductivity values of the top and bottom most layers are comparatively lesser among all the vadose-zone layers, while the highest value was found in the root zone (layer 2: 0.1-0.3 m). Compactness of both the layers may play a vital role behind this. In low moisture range, the hydraulic conductivity value of top layer (sandy loam) is greater than that in the bottom most layer, while in high moisture range, the hydraulic conductivity is higher in the bottom most layer (sandy clay loam). Much steeper $K-\theta$ curves in low moisture range are also apparent from figure 7 .

\section{Conclusions}

The field investigation carried out in the lateritic vadose zone of the study area revealed that the $K_{\mathrm{fs}}$ values range from 0.39 to $6.77 \mathrm{~cm} /$ day for the barren land, 0.031 to $19.79 \mathrm{~cm} /$ day for the cultivated land and 2.52 to $18.32 \mathrm{~cm} /$ day for the orchard area. Although the effect of different land uses on the $K_{\mathrm{fs}}$ of the study area is not statistically significant, the mean values of $K_{\mathrm{fs}}$ in the barren land (mean $K_{\mathrm{fs}}=3.72 \mathrm{~cm} /$ day), cultivated land (mean $K_{\mathrm{fs}}=7.26 \mathrm{~cm} /$ day) and orchard area (mean $K_{\mathrm{fs}}=9.45 \mathrm{~cm} /$ day) vary considerably from a practical point of view. In contrast, the depth-wise variation of $K_{\mathrm{fs}}$ in the study area was found to be statistically significant. Moreover, the depth-wise performance assessment 
of the PTFs revealed that the $\mathrm{R}-\mathrm{B} / \mathrm{C}-\mathrm{G}$ method can predict somewhat better in deeper lateriticvadose-zone layers mostly having finer 'sandy clay loam' type texture, while Model 3 of Rosetta performs well to some extent in shallow layers mostly having coarse-textured soils. The performance of the PTFs varies considerably for the vadose-zone layers even for similar textured layers. This finding implies that the importance of bulk density and effective porosity should not be ignored for estimating the saturated hydraulic conductivity. Based on the statistical indicators, it is concluded that Model 3 of Rosetta is capable of predicting relatively close values of saturated hydraulic conductivity for the lateritic vadose zones to some extent. However, all the PTFs used in this study generally fail to yield reasonable values of in-situ hydraulic conductivity of lateritic vadose zones.

The findings of this study emphasise the urgent need for considering both spatial and depth-wise variation of hydraulic and physical parameters of the vadose zone while studying groundwater recharge and contaminant transport processes through unsaturated porous media. Finally, to generalise the findings of this study, such field-based studies should be carried out in future at a larger scale considering larger data sets and more number of locations with varying land use/land cover. Future attempts should also be made to develop more reliable PTFs for lateritic vadose zones. Also, creating additional data of the lateritic vadose zones such as organic matter content and soil water retention parameters at a larger scale will be useful for the rigorous evaluation of existing sophisticated and data-intensive PTFs. These future studies will be helpful in better planning and management of land and water resources at a watershed/catchment scale. In future, further studies may be carried out to evaluate the performance of PTFs in other alluvial terrains and hard-rock terrains.

\section{Acknowledgements}

The authors are very grateful to the Ministry of Human Resource Development, New Delhi, India, for their financial support in terms of fellowship and research project due to which the present study could be completed. They are also very thankful to the Associate Editor and the anonymous reviewers for their meticulous and constructive comments/suggestions.

\section{References}

Bagarello V 1997 Influence of well preparation on fieldsaturated hydraulic conductivity measured with the Guelph Permeameter; Geoderma 80(1-2) 169-180.

Bagarello V, D'Asaro F and Iovino M 2012 A field assessment of the Simplified Falling Head technique to measure the saturated soil hydraulic conductivity; Geoderma 18749 58.

Balfour V N 2015 Determining wildfire ash saturated hydraulic conductivity and sorptivity with laboratory and field methods; Catena 135 358-368.

Balland V, Pollacco J A P and Arp P A 2008 Modeling soil hydraulic properties for a wide range of soil conditions; Ecol. Model. 219(3-4) 300-316.

Behera S, Jha M K and Kar S 2003 Dynamics of water flow and fertilizer solute leaching in lateritic soils of Kharagpur region, India; Agric. Water Manag. 63(2) 77-98.

Bouwer H 1966 Rapid field measurement of air entry value and hydraulic conductivity of soil as significant parameters in flow system analysis; Water Resour. Res. 2(4) 729-738.

Campbell G S 1985 Soil physics with BASIC: Transport models for soil-plant systems; Elsevier, New York.

Cosby B J, Hornberger G M, Clapp R B and Ginn T R 1984 A statistical exploration of soil moisture characteristics to the physical properties of soils; Water Resour. Res. 20 682-690.

Cronican A E and Gribb M M 2004 Hydraulic conductivity prediction for sandy soils; Groundwater 42(3) 459-464.

Dane J H and Puckett W 1994 Field soil hydraulic properties based on physical and mineralogical information; In: Proceedings of the international workshop on indirect methods for estimating the hydraulic properties of unsaturated soils (eds) Theodorus M, Van G, Leij F J and Lund L J, University of California: Riverside, CA, pp. 389-403.

Daniel D E 1982 Measurement of hydraulic conductivity of unsaturated soils with thermocouple psychrometers; Soil Sci. Soc. Am. J. 46(6) 1125-1129.

Dann R, Close M, Flintoft M, Hector R, Barlow H, Thomas $\mathrm{S}$ and Francis G 2009 Characterization and estimation of hydraulic properties in an alluvial gravel vadose zone; Vadose Zone J. 8(3) 651-663.

Duan R, Fedler C B and Borrelli J 2012 Comparison of methods to estimate saturated hydraulic conductivity in Texas soils with grass; J. Irrig. Drain. Eng. 138(4) 322327.

Elrick D E, Reynolds W D and Tan K A 1989 Hydraulic conductivity measurements in the unsaturated zone using improved well analyses; Groundwater Monit. Remediat. 9(3) 184-193.

Garg K K, Jha M K and Kar S 2005 Field investigation of water movement and nitrate transport under perched water table conditions; Biosyst. Eng. 92(1) 69-84.

Gupta R K, Rudra R P, Dickinson W T, Patni N K and Wall G J 1993 Comparison of saturated hydraulic conductivity measured by various field methods; Trans. ASAE $\mathbf{3 6 ( 1 )}$ $51-55$.

Hangen E and Vieten F 2018 A comparison of five different techniques to determine hydraulic conductivity of a riparian soil in North Bavaria, Germany; Pedosphere 28(3) 443-450. 
Hermsmeyer D, Ilsemann J, Bachmann J, Van Der Ploeg R $\mathrm{R}$ and Horton R 2002 Model calculations of water dynamics in lysimeters filled with granular industrial wastes; J. Plant Nutr. Soil Sci. 165(3) 339-346.

Jačka L, Pavlásek J, Kuráž V and Pech P 2014 A comparison of three measuring methods for estimating the saturated hydraulic conductivity in the shallow subsurface layer of mountain podzols; Geoderma 219 82-88.

Lee D M, Elrick D, Reynolds W and Clothier B E 1985 A comparison of three field methods for measuring saturated hydraulic conductivity; Can. J. Soil Sci. 65(3) 563573.

Li Y, Chen D, White R E, Zhu A and Zhang J 2007 Estimating soil hydraulic properties of Fengqiu County soils in the North China Plain using pedo-transfer functions; Geoderma 138(3) 261-271.

Libardi P L, Reichardt K, Nielsen D R and Biggar J W 1980 Simple field methods for estimating soil hydraulic conductivity; Soil Sci. Soc. Am. J. 44(1) 3-7.

Machiwal D, Jha M K and Mal B C 2006 Modelling infiltrtaion and quantifying spatial soil variability in a watershed of Kharagpur, India; Biosyst. Eng. 95(4) 569 582.

Manyame C, Morgan C L, Heilman J L, Fatondji D, Gerard B and Payne W A 2007 Modeling hydraulic properties of sandy soils of Niger using pedotransfer functions; Geoderma 141(3) 407-415.

Minasny B and McBratney A B 2000 Evaluation and development of hydraulic conductivity pedotransfer functions for Australian soil; Soil Res. 38(4) 905-926.

Nandagiri L, Bore Gowda S B and Shetty A 2006 In-situ characterization of unsaturated soil hydraulic properties of a laterite soil profile in coastal Karnataka; ISH J. Hydraul. Eng. 12(1) 87-98.

Nimmo J R 2005 Unsaturated zone flow processes; In: Encyclopedia of hydrological sciences, part 13-groundwater (eds) Anderson M G and Bear J, Wiley, Chichester, UK, Vol. 4, pp. 2299-2322.

Pachepsky Y A, Rawls W J and Timlin D J 1999 The current status of pedo transfer functions: Their accuracy, reliability, and utility in field and regional-scale modeling; In: Assessment of non-point source pollution in the vadose zone, Geophys. Monograph Ser. 108 223-234.

Puhlmann H and von Wilpert K 2012 Pedotransfer functions for water retention and unsaturated hydraulic conductivity of forest soils; J. Plant Nutr. Soil Sci. 175(2) 221235.

Rasoulzadeh A and Yaghoubi A 2011 Study of cattle manure effect on soil hydraulic properties using inverse method; In: 2nd International conference on environmental science and technology (ICEST), Singapore, pp. 26-28.

Rawls W J and Brakensiek D L 1989 Estimation of soil water retention and hydraulic properties; In: Unsaturated flow in hydrologic modeling, Springer, The Netherlands, pp. 275300.

Raychaudhuri S P 1980 The occurrence, distribution, classification and management of laterite and lateritic soils; Cah. ORSTOM, Pedologie 18(3-4) 249-252.

Reynolds W D and Elrick D E 1985 In-situ measurement of field-saturated hydraulic conductivity, sorptivity and the alpha-parameter using the Guelph permeameter; Soil Sci. 140(4) 292-302.
Reynolds W D and Elrick D E 1989 A laboratory and numerical assessment of the Guelph permeameter method; Soil Sci. 144(4) 282-299.

Sander T and Gerke H H 2007 Preferential flow patterns in paddy fields using a dye tracer; Vadose Zone J. 6(1) 105-115.

Saxton K E, Rawls W J, Romberger J S and Papendick R I 1986 Estimating generalized soil-water characteristics from texture; Soil Sci. Soc. Am. J. 50 1031-1036.

Schaap M G, Leij F L and van Genuchten MT 1998 Neural network analysis for hierarchical prediction of soil hydraulic properties; Soil Sci. Soc. Am. J. $62847-$ 855.

Seki K, Ackerer P and Lehmann F 2015 Sequential estimation of hydraulic parameters in layered soil using limited data; Geoderma 247 117-128.

Shin Y, Mohanty B P and Ines A V 2012 Soil hydraulic properties in one-dimensional layered soil profile using layer-specific soil moisture assimilation scheme; Water Resour. Res., https://doi.org/10.1029/2010WR009581.

Smettem K R J and Bristow K L 1999 Obtaining soil hydraulic properties for water balance and leaching models from survey data. 2. Hydraulic conductivity; Aust. J. Agric. Res. 50(7) 1259-1262.

Sobieraj J A, Elsenbeer H and Vertessy R A 2001 Pedotransfer functions for estimating saturated hydraulic conductivity: Implications for modeling storm flow generation; J. Hydrol. 251(3-4) 202-220.

Stephens D B, Lambert K and Watson D 1984 Influence of entrapped air on field determinations of hydraulic properties in the vadose zone; In: Proceedings of conference on characterization and monitoring in the vadose zone, Las Vegas, Nevada, pp. 57-76.

Tardy Y 1997 Petrology of laterites and tropical soils; A.A. Balkema, Rotterdam, The Netherlands, 408p.

Tietje O and Hennings V 1996 Accuracy of the saturated hydraulic conductivity prediction by pedo-transfer functions compared to the variability within FAO textural classes; Geoderma 69(1) 71-84.

Ungaro F, Calzolari C and Busoni E 2005 Development of pedotransfer functions using a group method of data handling for the soil of the Pianura Padano-Veneta region of North Italy: Water retention properties; Geoderma 124(3) 293-317.

Wagner B, Tarnawski V R, Hennings V, Müller U, Wessolek G and Plagge R 2001 Evaluation of pedo-transfer functions for unsaturated soil hydraulic conductivity using an independent data set; Geoderma 102(3) 275297.

Wagner B, Tarnawski V R and Stöckl M 2004 Evaluation of pedotransfer functions predicting hydraulic properties of soils and deeper sediments; J. Plant Nutr. Soil Sci. 167(2) 236-245.

Wang Y, Shao M A and Liu Z 2012 Pedotransfer functions for predicting soil hydraulic properties of the Chinese Loess Plateau; Soil Sci. 177(7) 424-432.

Wösten J H M 1997 Pedotransfer functions to evaluate soil quality; Dev. Soil Sci. 25 221-245.

Wösten J H M, Finke P A and Jansen M J W 1995 Comparison of class and continuous pedotransfer functions to generate soil hydraulic characteristics; Geoderma 66(34) $227-237$. 
Yao R J, Yang J S, Wu D H, Li F R, Gao P and Wang X P 2015 Evaluation of pedotransfer functions for estimating saturated hydraulic conductivity in coastal salt-affected mud farmland; J. Soil Sedimentol. 15(4) 902-916.

Youngs E G 1968 An estimation of sorptivity for infiltration studies from moisture moment considerations; Soil Sci. 106(3) 157-163.

Corresponding editor: ABHiJit MukherJeE
Zhang S, Lövdahl L, Grip H and Tong Y 2007 Soil hydraulic properties of two loess soils in China measured by various field-scale and laboratory methods; Catena 69(3) 264273.

Zhao C, Shao M A, Jia X, Nasir M and Zhang C 2016 Using pedotransfer functions to estimate soil hydraulic conductivity in the Loess Plateau of China; Catena 143 1-6. 